\title{
PENGARUH JENIS REFRIGERANT DAN BEBAN PENDINGINAN TERHADAP KEMAMPUAN KERJA MESIN PENDINGIN
}

\author{
Edi Purwanto, Kemas Ridhuan \\ Program Studi Teknik Mesin Fakultas Teknik Universitas Muhammadiyan Metro \\ Jl. KH. Dewantara No. 116 Metro Telp. (0725) 45932-42445 Kode Pos 34111 \\ kmsridhuan@yahoo.co.id
}

\begin{abstract}
ABSTRAK
Setiap refrigerant memiliki sifat karakteristik yang berbeda yang mempengaruhi efek refrigerasi dan COP yang dihasilkan.Refrigerant R12 merupakan senyawa yang banyak digunakan dalam penyegar udara, penggunaan dalam bidang otomotif, sedangkan refrigerant R22 merupakan senyawa yang banyak digunakan dalam penyegar udara, penggunaan pada umumnya pendinginan ruangan dan unit temperature rendah.Beban pendinginan merupakan beban kalor atau panas yang keluarkan dan diserap oleh evaporator.Penelitian ini bertujuan untuk mengetahui pengaruh jenis refrigerant terhadap variasi beban pendinginan, karakteristik perubahan suhu yang terjadi dan pengaruhnya terhadap kemampuan kerja pendinginan. Penelitian dilakukan di kampus II Universitas Muhammadiyah Metro, metode yang digunakan pada penelitian ini adalah dengan cara melakukan pengujian alat, observasi lapangan, dan studi pustaka, kemudian melakukan pengambilan data yaitu pada AC dengan jenis refrigerant R12 dan R22 pada variasi beban 150 Watt, 300 Watt, 450 Watt, 600 Watt dan 750 Watt. Adapun hasil dari penelitian waktu pendinginan pada refrigerant R12 yaitu: 45; 60; $100 ; 120$ dan 130. Sedangkan pada refrigerant R22 yaitu: 53; 60; 70; 80 dan 93. Pada Refrigerant R12 lebih cocok untuk beban kecil sedangkan refrigerant R22 umtuk beban besar. Adapun COP yang didapat pada refrigerant R12 yaitu: 7,48; 6,44; 5,3; 5,78 dan 5,97, sedangkan pada refrigerant R22 yaitu: 21,02; 19,65; 19,06; 19,73 dan 21,109 .
\end{abstract}

Kata Kunci : AC, Refrigeran, Beban Pendinginan, COP.

\section{PENDAHULUAN}

Dalam kehidupan sehari-hari, manusia tentu saja menginginkan suatu keadaan dimana temperatur dan kelembaman ruangan lebih nyaman.Pada saat ini panas disekitar kita cukup tinggi, sehingga mengakibatkan kurang nyamanya pada saat seseorang melakukan aktifitas yang aktif didalam ruangan maupun diluar ruangan.Maka pada aktivitas didalam ruangan membutuhkan suatu alat yang dapat mengkondisikan ruangan tersebut pada suhu ideal supaya pada saat melaksanakan suatu aktifitas dapat berjalan dengan lancar dan nyaman.

Pengkondisian udara yang dimaksudkan adalah untuk memberikan kenyamanan dan kesegaran ruangan yang dikondisikan. Setiap ruangan mempunyai beban kalor yang berbeda dan hal ini akan mempengaruhi spesifikasi mesin pendingin AC yang akan dipakai. Ketepatan penentuan spesifikasi mesin AC yang sesuai, berpengaruh pada kesegaran dan kenyamanan di dalam ruangan. Dari perbedaan beban pendinginan terhadap jenis refrigerant yang digunakan tentu terdapat ukuran optimal yang ideal sehingga didapat kondisi kerja alat pendingin yang sesuai (COP mesin pendingin).

Mesin pendingin merupakan sebuah mekanisme berupa siklus yang mengambil energi (termal) dari daerah bertemperatur rendah dan dibuang ke daerah bertemperatur tinggi (lingkungan), sehingga beban pendinginan sangat berpengaruh terhadap prestasi mesin pendingin. Semakin besar beban pendinginan yang di dinginkan maka akan diperlukan daya mesin pendingin yang lebih besar. Begitu juga sebaliknya semakin kecil beban pendinginan maka lebih kecil daya mesin pendingin yang diperlukan.

Selain beban pendinginan, karakteristik dan jenis refrigerant juga berperan penting dalam meningkatkan proses pendinginan. Refrigerant merupakan fluida yang digunakan dalam siklus panas yang mengalami perubahan fase akibat tekanan.Refrigerant terdiri dari beberapa jenis, berbeda jenis refrigerant berbeda pula karakteristik yang terkandung dalam suatu refrigerant tersebut sehingga berpengaruh terhadap kemampuan dan kinerja mesin pendingin.Beberapa jenis refrigerant yang ada 
diantaranya refrigerant R12 dan refrigerant R22.Refrigerant R12 merupakan senyawa yang banyak digunakan dalam penyegar udara, dalam bidang otomotif, sedangkan refrigerant R22 merupakan senyawa yang banyak digunakan dalam penyegar udara, refrigerasi pada umumnya, pendinginan ruangan dan unit temperature rendah.Perbedaan antara dua refrigerant tersebut adalah titik didid dan titik pengembunan (Wiranto Aris Munandar; 1980).

Dari latar belakang diatas untuk mengetahui pengaruh jenis refrigerant terhadap beban pendinginan maka perlu adanya pengujian jenis - jenis refrigerant terhadap beberapa variasi beban pendinganan.

\section{LANDASAN TEORI}

\section{AC (Air Conditioner)}

Air Conditioner (AC) Merupakan sebuah alat yang mampu mengkondisikan udara. Dengan kata lain, AC (Air Conditioner) berfungsi sebagai penyejuk udara yang diinginkan ( sejuk atau dingin ) dan nyaman bagi tubuh. AC Lebih Banyak digunakan di wilayah yang beriklim tropis dengan kondisi temperatur udara yang relatif tinggi (panas).

\section{Sistem Refrigerasi}

Suatu penggunaan yang luas dari termodinamika adalah refrigerasi yaitu perpindahan panas dari temperatur yang rendah ke temperatur yang lebih tinggi. Sistem yang menghasilkan proses refrigerasi adalah refrigerator (atau pompa panas), dan siklusnya disebut siklus refrigerasi. Siklus refrigerasi yang banyak digunakan adalah siklus kompresi uap sederhana, dimana refrigeran diuapkan, dan dikodensasikan dengan jalan mengkompresi uap tersebut.Prinsip utama mesin refrigerasi adalah untuk menurunkan temperatur agar materi atau ruangan dapat terjaga temperaturnya sesuai dengan kebutuhan dan kenyamanan yang dikehendaki. Pada dasarnya sistem refrigerasi dibagi menjadi dua, yaitu:

a) Sistem refrigerasi mekanik

b) Sistem refrigerasi non mekanik

1. Sistem refrigerasi mekanik

Sistem refrigerasi ini menggunakan mesin mesin penggerak atau dan alat mekanik lain dalam menjalankan siklusnya. Yang termasuk dalam sistem refrigerasi mekanik di antaranya adalah:

a) Siklus Kompresi Uap (SKU)

b) Refrigerasi siklus udara

c) Kriogenik/refrigerasi temperatur ultra rendah

d) Siklus sterling

2. Sistem refrigerasi non mekanik

Berbeda dengan sistem refrigerasi mekanik, sistem ini tidak memerlukan mesin-mesin penggerak seperti kompresor dalam menjalankan siklusnya. Yang termasuk dalam sistem refrigerasi non mekanik di antaranya:

a) Refrigerasi termoelektrik

b) Refrigerasi siklus absorbsi

c) Refrigerasi steam jet

d) Refrigerasi magnetic

e) Heat pipe

\section{Siklus Kompresi Uap}

Dari sekian banyak jenis-jenis sistem refigerasi, namun yang paling umum digunakan adalah refrigerasi dengan sistem kompresi uap.Komponen utama dari sebuah siklus kompresi uap adalah kompresor, evaporator, kondensor dan katup

expansi

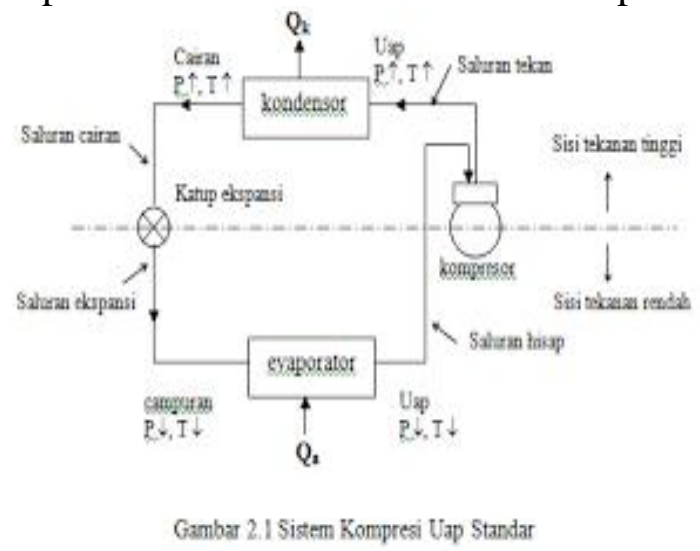

Gambar 1. Sistem kompresi uap standar

Sumber: (Muhammad Rizal, 2012)

\section{REFRIGERANT}

Refrigerant adalah fluida kerja utama pada suatu siklus refrigerasi yang bertugas menyerap panas pada temperatur dan tekanan rendah dan membuang panas pada temperatur dan tekanan tinggi. 


\section{Refrigerant R-12}

Refrigerant R12 merupakan senyawa hydrocholorocarbon yang memiliki nama lain $\mathrm{CC}_{2} \mathrm{LF}_{2}$ yang memiliki sufat stabil, tidak berbau, tidak berwarna baik dalam keadaan gas maupun cair, tidak mudah terbakar dan tidak korosif. Biasanya digunakkan pada penggerak kompresor gerak bolak balik, pendingin skala sedang yakni pada bidang otomotif.

\section{Refrigerant R-22}

Refrigerant R22 merupakan senyawa hydrocholorocarbon yang memiliki nama lain $\mathrm{CHCLF}_{2}$ yang memiliki memegang peranan penting dalam sistem refrigerasi, sejak ditemukan pada tahun 1930. Hal ini dikarenakan CFC memiliki properti fisika dan termal yang baik sebagai refrigeran, stabil, tidak mudah terbakar, tidak beracun dan kompatibel terhadap sebagian besar bahan komponen dalam sistem refrigerasi.Biasanya digunakkan pada $\mathrm{AC}$ rumah dengan kapasitas rendah sampai menegah.

\section{Beban pendinginan}

Perhitungan beban pendinginan merupakan hal yang utama dalam perancangan sistem pengkondisian udara.Hasil perhitungan tersebut nantinya dapat menentukan berapa besar kapasitas mesin refrigerasi yang dibutuhkan agar mampu mengkondisikan udara di dalam suatu ruangan sehingga terasa nyaman. Perhitungan beban pendinginan yang akurat akan berpengaruh terhadap optimasi dimensi mesin refrigerasi yang direncanakan. Beban pendinginan dibagi menjadi dua yaitu beban pendinginan sensibel dan beban pendinginan laten

\section{Perhitungan Dalam Sistem Refrigerasi}

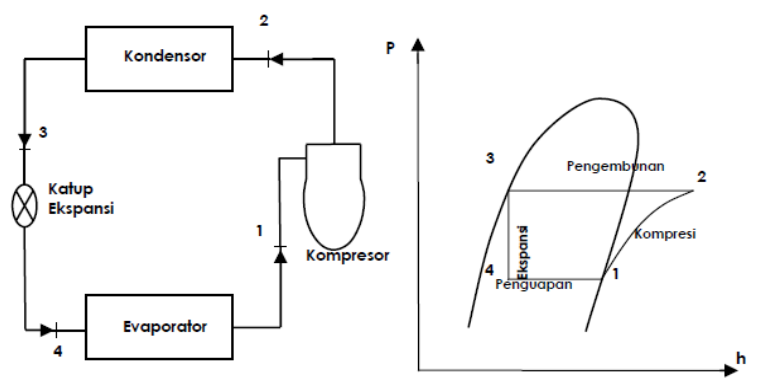

Gambar 2.Diagram $\mathrm{P}$ - h siklus kompresi uap ideal
1. Besarnya kerja kompresi per satuan massa refrigerant.

$$
Q_{w}=h_{2}-h_{1} \quad \text { (Supratman Hara,1982) }
$$

Dimana :

$Q_{w}=$ Besarnya kerja kompresor $(\mathrm{kJ} / \mathrm{kg})$

$h_{l}=$ Entalpi refrigeran saat keluar evaporator dan masuk kompresor $(\mathrm{kJ} / \mathrm{kg})$

$h_{2}=$ Entalpi refrigerant saat keluar kompresor dan masuk kondensor $(\mathrm{kJ} / \mathrm{kg})$

2. Besar panas per satuan massa refrigeran yang dilepaskan di kondensor dinyatakan sebagai:

$Q_{c}=h_{2}-h_{3}$

( Supratman Hara,1982 )

Dimana :

$Q_{c}=$ Besarnya panas dilepas di kondensor $(\mathrm{kJ} / \mathrm{kg})$

$h_{2}=$ Entalpi refrigerant saat keluar kompresor dan masuk kondensor $(\mathrm{kJ} / \mathrm{kg})$

$h_{3}=$ Entalpi refrigeran saat keluar kondensor $(\mathrm{kJ} / \mathrm{kg})$

3. Besarnya kalor yang diserap oleh evaporator $Q_{e}=h_{1}-h_{4} \quad$ (Supratman Hara,1982)

Dimana :

$Q_{e}=$ Besarnya panas yang diserap di evaporator $(\mathrm{kJ} / \mathrm{kg})$

$h_{l}=$ Entalpi refrigeran saat keluar evaporator dan masuk kompresor $(\mathrm{kJ} / \mathrm{kg})$

$h_{4}=$ Entalpi refrigeran saat masuk evaporator, $(\mathrm{kJ} / \mathrm{kg})$

4. Koefisien Prestasi / Coefficient of Performance (COP)

Koefisien prestasi dari sistem refrigerasi adalah dampak refrigerasi (efek refrigerasi) dibagi dengan kerja kompresi.

$$
\begin{aligned}
\text { COP } & =\frac{\text { dampak refrigerasi }}{\text { kerja kompresi }} \\
& =\frac{h_{1}-h_{4}}{h_{2}-h_{1}} \quad \text { (Supratman Hara, 1982) }
\end{aligned}
$$

Dimana :

$h_{l}=$ Entalpi refrigerant saat keluar evaporator dan masuk kompresor $(\mathrm{kJ} / \mathrm{kg})$

$h_{2}=$ Entalpi refrigerant saat keluar kompresor dan masuk kondensor $(\mathrm{kJ} / \mathrm{kg})$

$h_{4}=$ Entalpi refrigerant saat masuk evaporator, $(\mathrm{kJ} / \mathrm{kg})$ 


\section{METODE PENELITIAN}

Metode yang kali lakukan adalah tinjauan lapangan ( observasi ), kajian pustaka, dan data eksperimen (pengujian alat).Alat uji di rangkai menggunakan AC yang di pasang diruangan tertutup dengan beban pendinginan yang divariaskan.

\section{Desain Alat Uji}

Persiapan alat uji (pengecekan dan perbaikan), Unit indoor AC dipasang di dalam ruangan,Unit outdoor AC dipasang di luar ruangan, Hubungkan kabel suplai tegangan listrik dari indor menuju unit outdoor AC, Isikan refrigerant R22 pada pengujian yang pertama dan refrigerant R12 pada pengujian yang kedua, Pasang pengukur temperatur termokopel pada pipa masuk evaporator $\left(\mathrm{T}_{1}\right)$, pipa keluar evaporator $\left(\mathrm{T}_{2}\right)$, pipa masuk kompresor $\left(\mathrm{T}_{3}\right)$, pipa masuk kondensor $\left(\mathrm{T}_{4}\right)$, pipa keluar kondensor $\left(\mathrm{T}_{5}\right)$, Pasang pengukur hembusan kondensor psychrometer $\left(\mathrm{T}_{6}\right)$, hembusan evaporator $\left(\mathrm{T}_{7}\right)$, pada ruangan $\left(\mathrm{T}_{8}\right)$ dan anymeter pada kelembaban ruangan $\left(\mathrm{T}_{9}\right)$. Masing-masng temperatur yang melalui kabel dipasang nanti akan menunjukan berapa besar temperatur yang terjadi sebagai data acuan.

\section{Tahap Pengujian Alat}

Siapkan alat ukur dan unit AC, Pasang unit indoor AC pada ruangan, Pasang unit outdoor AC, Pasang 2 buah pipa penghubung antara indoor unit dan outdoor unit, pastikan pipa terpasang dengan benar dan rapat, Pasang kabel suplai tegangan listrik dari indoor unit menuju output AC, Pasang gauge manifold pada nepel pengisisan, Sebelum unit AC diisi refrigeran terlebih dulu divakum dengan mesin vakum, Isi refrigerant R22 sampai pada tekanan standar pada pengujian yang pertama, Operasikan sistem mesin pendingin dengan variasi beban pengujian yang berbeda yaitu: 150 Watt, 300 Watt, 450 Watt, 600 Watt dan 750 Watt, Catat perubahan temperatur yang ditunjukkan oleh alat ukur setiap 10 menit sampai temperatur ruangan pada kondisi nyaman $23^{\circ} \mathrm{C}$, Setelah pengambilan data pada pengujian yang pertama dengan refrigerant $\mathrm{R} 22$ dan refrigerant $\mathrm{R} 12$.

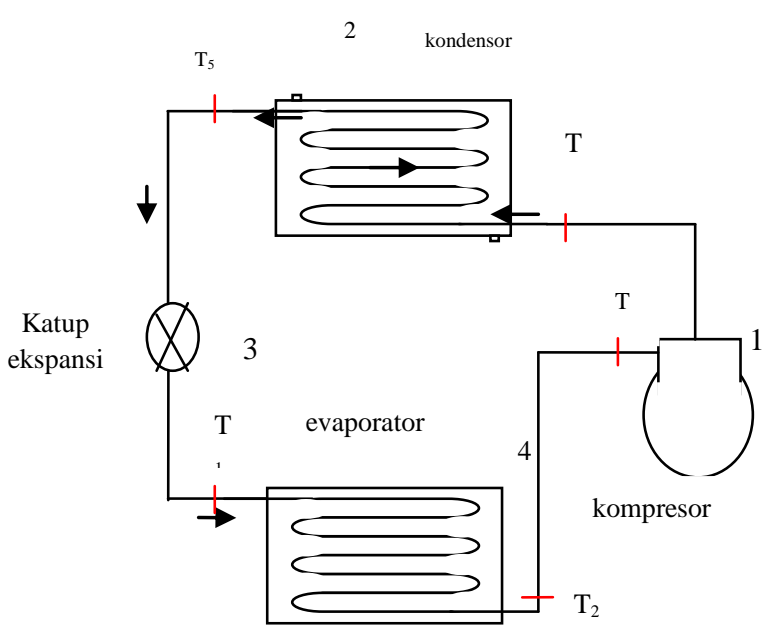

Gambar 3. Skema alat uji

\section{HASIL DAN PEMBAHASAN}

\section{Hasil Pengujian Alat}

Dari hasil pengujian dan pengukuran diperoleh beberapa data diantaranya adalah : Refrigerant R12 dengfan beban pendinginan 300 Watt, 450 Watt, 600 Watt dan 750 watt. Refrigerant R22 dengfan beban pendinginan 300 Watt, 450 Watt, 600 Watt dan 750 watt.

\section{Pembahasan}

Hubungan Waktu Pendinginan Terhadap Beban Pendiginan Refrigerant R12 Dan Refrigerant R22

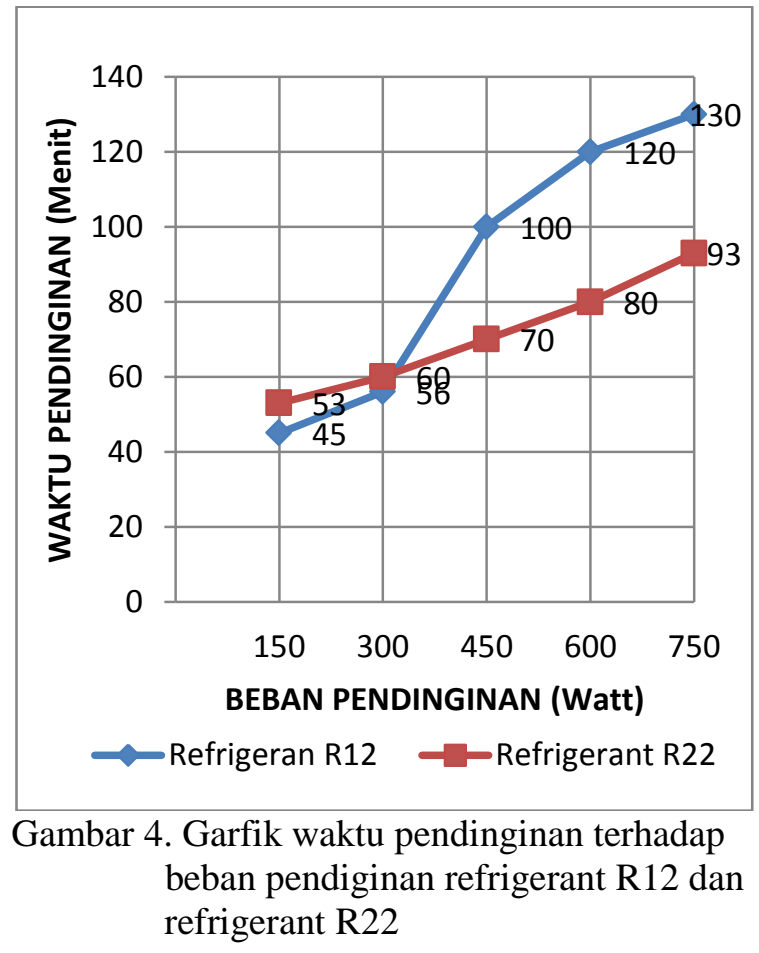


Berdasarkan Garfik waktu pendinginan terhadap beban pendiginan refrigerant R12 dan refrigerant R22 pada Gambar 4. di atas dengan menggunakan refrigerant R12 dengan variasi beban 150 Watt, 300 watt, 450 Watt, 600 Watt dan 750 Watt. Pada refrigerant R12 dengan beban 150 Watt waktu yang dibutuhkan untuk mencapai suhu ideal $\left(23^{0} \mathrm{C}\right)$ lebih cepat dibandingan dengan refrigerant R22 yaitu 45 menit sedangkan pada refrigerant R22 dengan beban 150 Watt yaitu 53 menit.

Dan pada refrigerant R12 dengan beban 750 Watt waktu yang dibutuhkan untuk mencapai suhu ideal $\left(23^{\circ} \mathrm{C}\right)$ lebih lama dibandingan dengan refrigerant R22 yaitu 130 menit sedangkan pada refrigerant R22 dengan beban 150 Watt yaitu 93 menit. Jadi dapat di simpulkan bahwa pada pengguanan beban yang kecil (diawah beban 300 Watt) sebaiknya menggunakan refrigerant R12 dan pada beban yang lebih besar (diatas beban 300 Watt) pada ruangan yang sama menggunakan refrigerant R22 karena lebih cepat dalam waktu pendinginan.

Hubungan Temperatur Masuk Evaporator Terhadap Beban Pendiginan Refrigerant R12 Dan Refrigerant R22

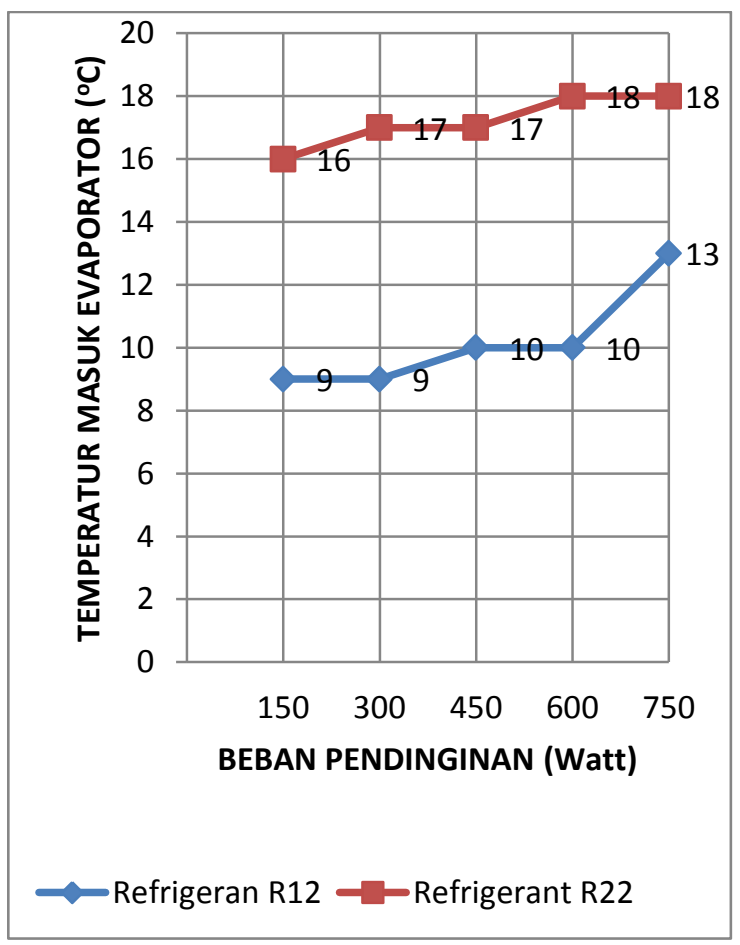

Gambar 5.Garfik temperatur masuk evaporator terhadap beban pendiginan refrigerant $\mathrm{R} 12$ dan refrigerant $\mathrm{R} 22$
Rrefrigerant R12 dan refrigerant R22 pada variasi beban 150 Watt, 300 watt, 450 Watt, 600 Watt dan 750 Watt menunjukkan perbedaan yang sangat besar yaitu pada temperatur masuk evaporator, waktu pendinginan untuk mencapai temperatur ideal yaitu $23^{\circ} \mathrm{C}$ pada temperature ruangan. Pada refrigerant $\mathrm{R} 12$ temperatur masuk evaporator yaitu mencapai $9^{0} \mathrm{C}$ dan pada temperatur tertinggi yaitu mencapai $60^{\circ} \mathrm{C}$.sedangkan pada refrigerant R22 temperatur masuk evaporator yaitu mencapai $16^{\circ} \mathrm{C}$ dan pada temperatur tertinggi yaitu mencapai $69^{\circ} \mathrm{C}$. Perbedaan ini dipengaruhi kerena perbedaan kapasitas pendinginan.

Hubungan COP Pendinginan Terhadap Beban Pendiginan Refrigerant R12 Dan Refrigerant R22

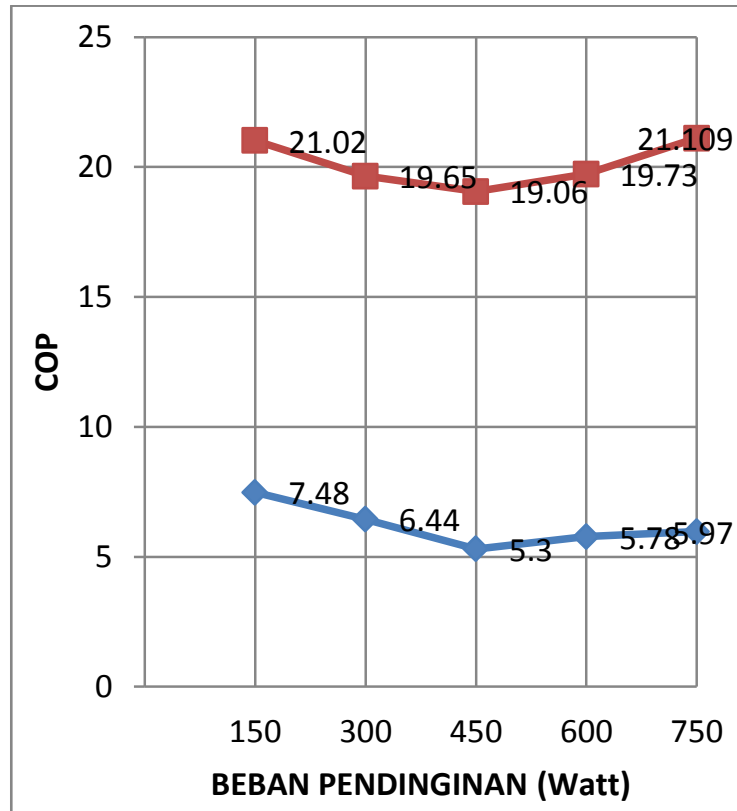

$\longrightarrow$ Refrigeran R12 $\quad$ Refrigerant R22

Gambar 6. Grafik COP pendinginan terhadap beban pendiginan refrigerant $\mathrm{R} 12$ dan refrigerant $\mathrm{R} 22$

Selain pada waktu pendinginan dan temperatur masuk evaporator, pada gambar 6 . COP pada refrigerant R12 pada beban 150 Watt terjadi sebesar 7,48 sedangkan pada refrigerant R22 pada beban 150 Watt terjadi sebesar 21,02. Dan pada refrigerant R12 pada beban 600 Watt terjadi kenaikan COP sebesar 5,78 yang sebelumnya pada beban 450 Watt COPnya sebesar 5,3 sedangkan pada refrigerant R22 
pada beban 600 Watt terjadi kenaikan COP sebesar 19,73 yang sebelumnya pada beban 450 Watt COPnya sebesar 19,03.

\section{Kesimpulan}

Dari hasil pengujian dan perhitungan yang telah dilakukan dapat disimpulkan antara lain:

1. Pada waktu pendinginan untuk ruangan yang sama Refrigerant R12 lebih cocok untuk beban kecil yaitu dibawah 300 Watt, sedangkan refrigerant R22 lebih cocok untuk beban besar yatiu diatas 300 Watt.

2. Perubahan suhu yang terjadi pada temperatur masuk evaporator pada kedua refrigerant relatif berbeda. Jadi temperatur masuk pada evaporator pada refrigerant R12 lebih kecil dibandingkan pada refrigerant R22.

3. Kemampuan kerja mesin pendingin (COP) pada refrigerant R22 lebih besar dibandingkan dengan refrigerant R12.

\section{DAFTAR PUSTAKA}

1. Galuh Renggani Willis. Penggunaan refrigerant pada mesin pendingin. Universitas sumatera utara. 2007

2. Muhammad Rizal, Perancangan Ulang Mesin Ac Split Kapasitas 2 Pk.Politeknik Negeri Bali. 2012

3. Saad Michel A. Termodinamika Prisip Dan Aplikasi. Edisi Pertama. PT Prenhallindo. Jakarta. 2000

4. Supratman H. Refrigerasi Dan Pengkondisian Udara, Edisi Kedua, Erlangga, Jakarta, 1982

5. Wahyu T, sumaryanto D. Pedoman Praktis Merawat Ac Mobil. Erlangga. 2011

6. Universitas Muhammadiyah Metro. Pedoman Penulisan Karya Ilmiah Strata 1, Universitas Muhammadiyah Metro. 2008

7. Wiranto Arismunandar, H.Saito Penyegaran Udara. Edisi keempat, PT. Pradnya Paramita, Jakarta. 1980. 